\title{
ARTICLE
}

\section{The effects of interactions between proline and carbon nanostructures on organocatalysis in the Hajos-Parrish-Eder-Sauer-Wiechert reaction}

Received 00th January 2012, Accepted 00th January 2012

DOI: $10.1039 / \times 0 \times x 00000 x$

www.rsc.org/

\author{
G.A. Rance ${ }^{a *}$ and A.N. Khlobystov ${ }^{a, b}$
}

The non-covalent interactions of $S$-(-)-proline with the surfaces of carbon nanostructures (fullerene, nanotubes and graphite) change the nucleophilic-electrophilic and acid-base properties of the amino acid, thus tuning its activity and selectivity in the organocatalytic HajosParrish-Eder-Sauer-Wiechert (HPESW) reaction. Whilst our spectroscopy and microscopy measurements show no permanent covalent bonding between $S$-(-)-proline and carbon nanostructures, a systematic investigation of the catalytic activity and selectivity of the organocatalyst in the HPESW reaction demonstrates a clear correlation between the pyramidalisation angle of carbon nanostructures and the catalytic properties of $S$-(-)-proline. Carbon nanostructures with larger pyramidalisation angles have a stronger interaction with the nitrogen atom lone pair of electrons of the organocatalyst, thereby simultaneously decreasing the nucleophilicity and increasing the acidity of the organocatalyst. These translate into lower conversion rates but higher selectivities towards the dehydrated product of Aldol addition.

\section{Introduction}

The yields and distribution of products of catalysed chemical reactions are critically dependent on the properties the catalyst. ${ }^{1}$ Over millennia, living organisms have evolved to catalyse a broad range of specific chemical transformations in enzymatic systems with great efficiency. More recently, synthetic chemists have attempted to replicate enzymatic behaviour and generate new catalytic systems to meet the demands of modern society. ${ }^{2}$ However, novel catalyst design and synthesis imposes a significant challenge, involving complex molecular functionalisation and evaluation of structure-function relationships, which can be both time consuming and expensive. A more attractive approach would be to utilise the non-covalent interactions between the catalyst and an auxiliary species to tune the properties of the catalyst.

Organocatalysts are small organic molecules predominantly composed of $\mathrm{C}, \mathrm{H}, \mathrm{O}, \mathrm{N}, \mathrm{S}$ and $\mathrm{P}$ that accelerate chemical reactions and possess many advantages over traditional metal catalysts, such as low cost, low toxicity, high availability and lack of sensitivity to moisture and oxygen. ${ }^{3}$ One of the most widely studied organocatalysts is the amino acid proline, largely due to its bioavailability and enantiopurity. ${ }^{4,5}$ Proline is a polar, zwitterionic molecule in aqueous solution and the solid state that has been used to catalyse a range of chemical transformations, ${ }^{6}$ including the Mannich reaction, ${ }^{7,8}$ Michael addition, ${ }^{9-11} \alpha-$ alkylation $^{12}$ and $\alpha$-amination of carbonyl compounds. ${ }^{13}$ In general, the organocatalytic reactions of proline are critically determined by the nucleophilic-electrophilic and acid-base properties of the endocyclic secondary amine and the exocyclic carboxylic acid, the balance of which can be readily modulated by non-covalent interactions with ancillary molecules. ${ }^{14}$ In this study, we utilise carbon nanostructures to tune the catalytic properties of proline in the Hajos-Parrish-Eder-Sauer-Wiechert (HPESW) reaction ${ }^{15,16}$ and demonstrate for the first time the principle that the known non-covalent interactions of amino acids with carbon nanostructures can be harnessed to control the activity and selectivity of organocatalysts for chemical transformations.

\section{Results and discussion}

The HPESW reaction was chosen for our proof-of-principle investigation to evaluate the effect of the interactions between carbon nanostructures and the organocatalyst proline (specifically the more common $S$-(-)-proline) on its catalytic properties (Fig. 1).

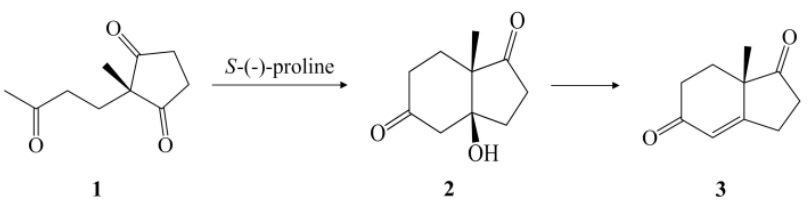

Fig. 1 The Hajos-Parrish-Eder-Sauer-Wiechert reaction. 
This classic organocatalytic reaction involves the intramolecular Aldol reaction of 2-methyl-2-(3-oxobutyl)cyclopentane-1,3dione 1 to yield 3a-hydroxy-7a-methylhexahydro-1H-indene1,5(6H)-dione 2 (the Hajos-Parrish ketol) as the product of Aldol addition and 7a-methyl-2,3,7,7a-tetrahydro-1H-indene-1,5(6H)dione 3 (the Hajos-Parrish ketone) as the product of subsequent dehydration (Fig. 1). ${ }^{15,16}$ Previous studies have shown that the conversion of $\mathbf{1}$ into products and the specific ratio of $\mathbf{2}$ to $\mathbf{3}$ depends on the experimental conditions and properties of the catalyst. ${ }^{17}$ For example, the reaction conducted in dimethylformamide yields exclusively $\mathbf{2},{ }^{15}$ whereas the use of chloroform yields a 54:46 distribution of 2:3. ${ }^{18}$ Furthermore, systematic investigations using prolines, prolinamides and other structural analogues reveal that modulation of the acid-base properties of the organocatalyst significantly affects the rate, selectivity of 2:3 and enantioselectivity of the reaction. ${ }^{18}$ Whilst a universally accepted mechanism for the HPESW reaction remains elusive, the most widely cited mechanistic pathway for conversion of $\mathbf{1}$ into $\mathbf{2}$ involves the carboxylic acid-facilitated formation of an enamine intermediate, the initial step of which involves the nucleophilic attack of the carbonyl of $\mathbf{1}$ by the nitrogen lone pair of electrons in proline. ${ }^{19}$ In addition, proline possesses both acidic and basic properties and can consequently influence the propensity of dehydration of the ketal into the ketone. Therefore, the precise balance between nucleophilicelectrophilic and acid-base properties of proline are essential in order to control the HPESW reaction, with the conversion of $\mathbf{1}$ into $\mathbf{2}$ being determined by nucleophilicity of the nitrogen and $\mathbf{2}$ into $\mathbf{3}$ being controlled by the availability of the proton (i.e. acidity of proline). In this study, we show for the first time that carbon nanostructures (fullerene, nanotubes and graphite) can affect both of these fundamental properties thus changing the reactions promoted by the organocatalyst.

The conversion of 1 catalysed by $10 \mathrm{~mol} \% \mathrm{~S}$-(-)-proline in deuterated chloroform after 7 days at room temperature is $73 \%$ and proceeds with a $\mathbf{2 : 3}$ selectivity of 66:34 (entry 8 , Table 1 ). It is important to note that long reaction times at low temperature are essential to avoid detrimental polymerisation (i.e. intermolecular reactions rather than intramolecular reactions). In a parallel reaction, the addition of single-walled carbon nanotubes (SWNT), synthesised by disproportionation of carbon monoxide over mixed $\mathrm{Co}$ and Mo catalysts (the CoMoCAT process) and possessing a mean diameter of $0.73 \pm 0.10 \mathrm{~nm}$, had a remarkable effect on both the yield (38\% decrease) and distribution of products ( $21 \%$ increase in 2) of the HPESW reaction (entry 2, Table 1) and clearly shows that carbon nanotubes influence the properties of the organocatalyst. No effect on the enantioselectivity of either $\mathbf{2}$ or $\mathbf{3}$ was observed (Table S1, ESI $\dagger$ ). Furthermore, no products were formed in the presence of CoMoCAT SWNT, in the absence of proline, indicating that neither the nanotube itself or any of the byproducts of carbon nanotube synthesis and processing possess any inherent organocatalytic activity.

In an attempt to explore our experimental observations, further control experiments in the absence of carbon nanotubes were performed. Systematic variation of both reactant concentration and organocatalyst loading resulted in a similar effect to that observed by the addition of carbon nanotubes, with lower concentrations and catalyst loadings resulting in analogous decreases in conversion and increases in Aldol selectivity (Figs. $\mathrm{S} 1$ and $\mathrm{S} 2, \mathrm{ESI} \dagger)$. This could imply that carbon nanotubes simply sequester either $\mathbf{1}$ and/or proline from the bulk solution, decreasing the concentration of both reactant and organocatalyst and in turn affecting the yield and distribution of products of the HPESW reaction. However, if molecular binding to carbon nanotubes were prevalent, we would expect to be able to determine the extent of this association. Yet, our Raman spectroscopy measurements of carbon nanotubes before and after the HPESW reaction (Fig. S3 and Table S2, ESI $\dagger$ ) showed effectively no change in the $I_{D} / I_{G}$ ratio or the frequency of the radial breathing modes ( $\mathrm{RBMs}$ ) or $\mathrm{G}$ band, thus indicating that permanent chemi- or physisorption of the organocatalyst onto carbon nanotubes does not occur. Furthermore, transmission electron microscopy (Fig. S4, ESI $\dagger$ ) determined that no changes to the sidewall structure of the carbon nanotubes were observed under the conditions of the HPESW reaction. Moreover, titration measurements (Table S3, ESI $\dagger$ ) indicate that only $1.2 \%$ of $\mathbf{1}$ is sequestered by CoMoCAT SWNTs during the reaction. It is important to note that similar titration measurements assessing the affinity of the organocatalyst for carbon nanostructures could not be conducted due to the inherently low solubility of proline in chloroform; as such the reaction solvent is effectively saturated with proline in all experiments and thus the potential effect of organocatalyst concentration can be disregarded. Thus, the addition of carbon nanotubes has no significant influence on the concentration of either the reactant or the organocatalyst and hence the observed effect on the HPESW reaction is likely to be related to the altered properties of the organocatalyst by transient non-covalent interactions with carbon nanotubes.

Table 1. The effect of the interactions between $S$-(-)-proline catalyst and carbon nanostructures (single-walled carbon nanotube, SWNT; doublewalled carbon nanotube, DWNT; multi-walled carbon nanotube, MWNT; graphitised nanofibre, GNF; arc-discharge, AD) on the activity and selectivity of the organocatalyst in the HPESW reaction. ${ }^{a}$

\begin{tabular}{|c|c|c|c|c|}
\hline Entry & $\begin{array}{c}\text { Carbon } \\
\text { nanostructure }\end{array}$ & $\boldsymbol{\theta}_{\boldsymbol{p}} /^{\mathbf{0} \boldsymbol{b}}$ & $\begin{array}{c}\text { Conversion } \\
/ \boldsymbol{\%}^{\boldsymbol{c}}\end{array}$ & $\begin{array}{c}\mathbf{2 : 3} \\
\mathbf{s e l e c t i v i t y} \\
\mathbf{\%}^{\boldsymbol{c}}\end{array}$ \\
\hline 1 & $\mathrm{C}_{60}$-fullerene & 11.60 & 40 & $86: 14$ \\
\hline 2 & CoMoCAT SWNT & 4.72 & 35 & $87: 13$ \\
\hline 3 & AD SWNT & 2.01 & 40 & $86: 14$ \\
\hline 4 & DWNT & 0.61 & 47 & $80: 20$ \\
\hline 5 & MWNT & 0.09 & 57 & $75: 25$ \\
\hline 6 & GNF & 0.01 & 67 & $66: 34$ \\
\hline 7 & graphite & 0 & 65 & $67: 33$ \\
\hline 8 & none & - & 73 & $66: 34$ \\
\hline
\end{tabular}

${ }^{a}$ Standard conditions: carbon nanostructure $(5 \mathrm{mg}), S$-(-)-proline (10 mol\%), 2-methyl-2-(3-oxobutyl)cyclopentane-1,3-dione 1 (87 $\mu \mathrm{mol})$, deuterated chloroform $(1 \mathrm{~mL}), 7$ days, room temperature, dark; ${ }^{b}$ pyramidalisation angle $\left(\theta_{p}\right)$ was determined by statistical analysis of carbon nanostructure diameter $\left(d_{N T}\right.$, in $\AA$ ) by transmission electron microscopy, consistent with previous reports; ${ }^{20,21}{ }^{c}$ determined by ${ }^{1} \mathrm{H}$ NMR spectroscopy of the reaction mixture. The standard deviation of experimental values across multiple experiments is $\pm 3 \%$. 
Carbon nanotubes and fullerenes are known to form relatively strong non-covalent interactions with a wide range of amines ${ }^{22}$ and amino acids, ${ }^{23-27}$ including proline. ${ }^{28-31}$ Whilst the nature of interactions between proline and carbon nanostructures is still not definitively understood, the exact mechanism is likely to reflect a number of cooperative forces, including ionic interactions, ${ }^{32} \mathrm{~N}-\mathrm{H} \cdots \pi$ hydrogen bonding interactions ${ }^{33}$ and electron transfer interactions. ${ }^{34,35}$ Of these, the back-donation of the lone pair electrons from the occupied $\mathrm{N}$ non-bonding orbital on proline to the vacant $\mathrm{C}=\mathrm{C} \pi^{*}$ antibonding orbitals of the carbon nanotube appears to be the most important factor for controlling the proline-nanotube interaction (Fig. 2). ${ }^{36}$



$a_{1}$

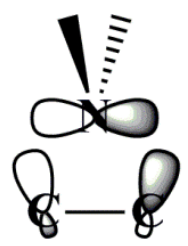

$b_{1}$
Fig. 2 Schematic depiction of the synergistic interactions between proline and carbon nanostructures, reflecting the balance of $\mathrm{C}=\mathrm{C} \pi$ to $\mathrm{N}$ $\mathrm{H}$ donative interactions of $a_{l}$ symmetry and $\mathrm{N}$ to $\mathrm{C}=\mathrm{C} \pi *$ back-donative interactions of $b_{1}$ symmetry. ${ }^{36}$

Moreover, the finite strength of these transient and reversible interactions modulates the absolute association and ultimate reactivity of amino acids with carbon nanotubes, the extent of which is critically dependent on the curvature of the nanotube surface. ${ }^{37,38}$ To explore the applicability of this phenomenon to our studies, we conducted a series of experiments using carbon nanostructures with different diameters and thus pyramidalisation angles of carbon atoms (Table 1). We anticipated that decreasing the diameter (increasing the pyramidalisation angle) of carbon nanostructures should increase the strength of proline-nanostructure interactions as a consequence of enhanced asymmetry of carbon $\pi$ orbital density on nanotubes (Fig. 3) and thus magnify the effect on the yields and products of the HPESW reaction.

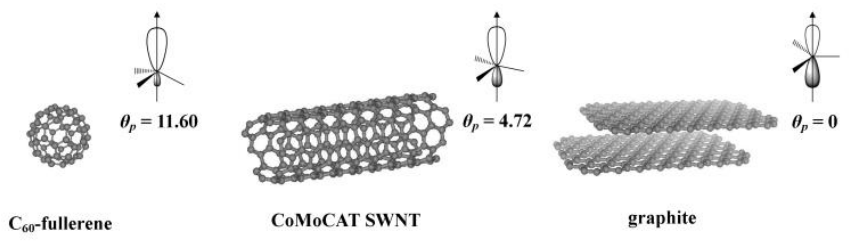

Fig. 3 The effect of carbon nanostructure pyramidalisation angle on the symmetry of the carbon $\pi$ orbitals. The arrow denotes the direction normal to the carbon nanostructure surface atoms.

Our measurements demonstrate the importance of pyramidalisation angle for controlling the properties of chemical reactions as we observed: (i) a general decrease in the conversion of $\mathbf{1}$ with increasing pyramidalisation angle and (ii) a general increase in the selectivity for $\mathbf{2}$ with increasing pyramidalisation angle (Fig 4.). For carbon nanostructures with low pyramidalisation angles, such as graphitised nanofibres and graphite $\left(\theta_{p}=0^{\circ}\right)$ the effects are small; however, for high pyramidalisation angle carbon nanostructures, such as $\mathrm{C}_{60}$ fullerene and narrow diameter carbon nanotubes, changes in the yields and distributions of products are clearly evident. It is important to note that this behaviour cannot be rationalised by the solubility of carbon nanostructures in chloroform, which is low in all cases tested and appears to show a solubility trend contradictory to the observed effect on the HPESW reaction (Fig. $\mathrm{S} 5, \mathrm{ESI} \dagger)$. The reduction in catalytic activity can be readily attributed to the decreasing nucleophilicity of the nitrogen lone pair of electrons on the amino acid upon association with carbon nanostructures and thus propensity to form the enamine intermediate.

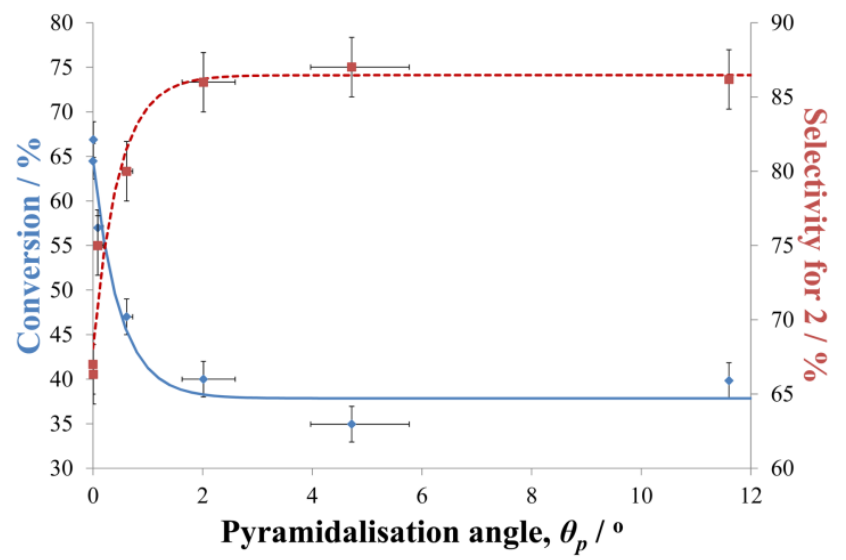

Fig. 4 The relationships between carbon nanostructure pyramidalisation angle and conversion into products (blue full line, $y=37.8+26.7 \mathrm{e}^{-2.1 x}$, $\mathrm{R}^{2}=0.95$ ) and selectivity for 2 (red dashed line, $y=86.4-18.4 \mathrm{e}^{-2.1 x}, \mathrm{R}^{2}$ $=0.92$ ) for data obtained from this series.

However, a side effect of the nitrogen of proline interacting with carbon nanostructures is that the proton of the carboxylic acid potentially becomes more available (Fig. 5).

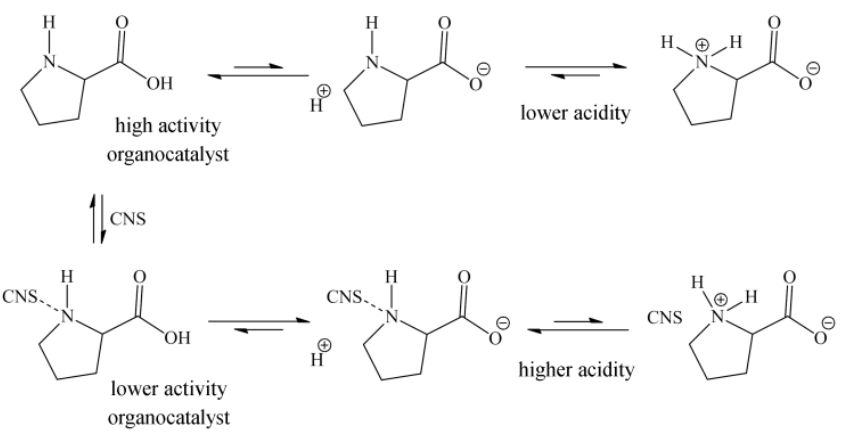

Fig. 5 The influence of interactions between proline and carbon nanostructures (CNS) on the acidity of the carboxylic acid proton. In the absence of carbon nanostructures, the availability of the proton is limited by the equilibrium between neutral and zwitterion forms and thus acidity 
is low. However, in the presence of carbon nanostructures, the lone pair on the $\mathrm{N}$-atom is involved in non-covalent interactions with CNS hindering the formation of the zwitterion and thus increases the acidity of the carboxylic acid.

This has important implications for the acid-catalysed dehydration of Aldol addition products, such as $\mathbf{2}$, the propensity of which is accelerated with decreasing pKa of the acid. ${ }^{17,39}$ Whilst our measurements would appear to indicate that carbon nanostructures with higher pyramidalisation angles impede the dehydration of $\mathbf{2}$ to $\mathbf{3}$ (Table 1), it is important to note that the absolute selectivity for the products $\mathbf{2}$ and $\mathbf{3}$ are critically dependent on the conversion of the starting material 1. It is known that in consecutive reactions such as this, an increase in the conversion of $\mathbf{1}$ will inevitably lead to a decrease in the selectivity for $\mathbf{2}$, as it becomes consumed to form $\mathbf{3}$. Indeed, our control measurements, in the absence of carbon nanotubes, indicate that as the reaction proceeds selectivity for $\mathbf{3}$ exponentially increases with conversion of 1 (Fig. S6, ESI $\dagger$ ). Therefore, as the observed $\mathbf{2 : 3}$ selectivities in the absence and presence of carbon nanostructures are recorded at different conversions, the values are not immediately comparable. However, when the selectivities for $\mathbf{3}$ are considered at identical conversions of $\mathbf{1}$ (Fig. S4, ESI $\dagger$ ) it becomes clear that a disproportionately high amount of $\mathbf{3}$ is afforded, at any given conversion, in the presence of carbon nanostructures. This implies that the interactions of the nitrogen lone pair of electrons with carbon nanostructures subtly increases the acidity of proline (i.e. lower the $\mathrm{pKa}$ of the carboxylic acid proton) and thus encourages the formation of $\mathbf{3}$ by acid-catalysed dehydration. Hence, the properties of organocatalytic reactions can be influenced by carbon nanostructures, the extent of which can be fine-tuned by careful selection of carbon nanotube curvature.

\section{Experimental}

\section{General Experimental.}

All reagents, including graphite, were purchased from SigmaAldrich, UK and used without further purification. Carbon nanotubes were purchased from a range of commercial suppliers: CoMoCAT SWNT (SG65 SWNT, Sigma Aldrich, synthesised by $\mathrm{CO}$ disproportionation, $\mathrm{d}=0.73 \pm 0.10 \mathrm{~nm}$ ), AD SWNT (Helix SWNT, Helix Material Solutions, synthesised by arc discharge, $\mathrm{d}=1.40 \pm 0.25 \mathrm{~nm}$ ), DWNT (Nanocyl 2100, Nanocyl, synthesised by chemical vapour deposition, $\mathrm{d}=3.48 \pm 0.42 \mathrm{~nm}$ ) MWNT (PD30L520 MWNT, NanoLab, synthesised by chemical vapour deposition, $\mathrm{d}=15.42 \pm 6.66 \mathrm{~nm}$ ) and GNF (PR24 GNF, Applied Science, synthesised by chemical vapour deposition, $\mathrm{d}$ $=114.55 \pm 40.66 \mathrm{~nm})$. C60-fullerene was purchased from SLS Research. Water was purified ( $>18 \mathrm{M} \Omega \mathrm{cm}$ ) using a Barnstead NANOPure II system. All glassware was cleaned with a mixture of hydrochloric and nitric acid (3:1 v/v, 'aqua regia') and rinsed thoroughly with deionised water, cleaned with potassium hydroxide in isopropyl alcohol and finally rinsed thoroughly with deionised water before use. ${ }^{1} \mathrm{H}$ and ${ }^{13} \mathrm{C}$ NMR spectra were obtained using a Bruker DPX-300 (300.13 and 75.4761 MHz respectively) spectrometer at $298 \mathrm{~K}$ using $\mathrm{CDCl}_{3}$ as the solvent. Mass spectrometry was conducted on a Bruker Apex IV using ESI in positive mode. Specific rotation was determined by polarimetry on a Bellingham Stanley ADP440 polarimeter at 22 ${ }^{\circ} \mathrm{C}$. Samples were made up to a concentration of $1 \mathrm{~g} 100 \mathrm{~mL}^{-1}$ in chloroform. Mean values of specific rotation were obtained from a minimum of two experiments. UV-vis spectra were recorded in solution using $1 \mathrm{~cm}$ quartz cuvettes using a Perkin-Elmer Lambda $25 \mathrm{UV}$-vis spectrophotometer at a scan rate of $480 \mathrm{~nm}$ $\mathrm{min}^{-1}$ over the range $250-900 \mathrm{~nm}$. Raman spectroscopy was conducted using a HoribaJY LabRAM HR spectrometer with a laser wavelength of $532 \mathrm{~nm}$. Samples were dropcast from methanolic solutions onto $\mathrm{Si}(100)$ wafers and a minimum of five spectra recorded from different areas of the sample. The spectra shown are the most representative of the averaged spectra. Transmission electron microscopy (TEM) imaging was performed using a JEOL 2100F TEM (field emission gun source, information limit $<0.19 \mathrm{~nm}, 200 \mathrm{kV}$ ) at room temperature. Samples were typically prepared by casting several drops of solution onto either copper-grid mounted "lacey" carbon films, dried under a stream of nitrogen. Dynamic light scattering (DLS) was performed using a Malvern Instruments Nano-ZS Zetasizer at room temperature. Quoted values are the average of 3 measurements.

\section{Preparation of 2-methyl-2-(3-oxobutyl)cyclopentane-1,3- dione 1.}

To 2-methyl-1,3-cyclopentanedione (9.23 $\mathrm{g}, 82.3 \mathrm{mmol})$ in deionised water $(13 \mathrm{~mL})$ was added glacial acetic acid $(0.3 \mathrm{~mL})$ and methylvinylketone $(11.5 \mathrm{~mL}, 138.0 \mathrm{mmol})$ and the combined mixture was heated at $75{ }^{\circ} \mathrm{C}$ for $14 \mathrm{hr}$. The crude product was extracted with dichloromethane (3 x $150 \mathrm{~mL})$, washed with brine ( 2 x $100 \mathrm{~mL})$, dried over sodium sulphate, filtered and the solvent removed in vacuo. The product was obtained by silica gel column chromatography (petroleum ether / ethyl acetate, 3 / 2) as a colourless oil (14.5 g, 96\%). $\mathrm{R}_{\mathrm{f}} 0.32$ (petroleum ether / ethyl acetate, $3 / 2) ;{ }^{1} \mathrm{H} \mathrm{NMR}\left(\mathrm{CDCl}_{3}\right) \delta_{\mathrm{H}} / \mathrm{ppm}$ 2.90-2.68 (m, 4H), 2.45 (t, 2H, $J=7.2 \mathrm{~Hz}), 2.09$ (s, 3H), $1.88(\mathrm{t}$, $2 \mathrm{H}, J=7.2 \mathrm{~Hz}), 1.10(\mathrm{~s}, 3 \mathrm{H}) ;{ }^{13} \mathrm{C} \mathrm{NMR}\left(\mathrm{CDCl}_{3}\right) \delta \mathrm{c} / \mathrm{ppm} 215.7$, 207.7, 54.9, 37.2, 34.5, 29.8, 27.6, 18.8; HRMS $\mathrm{m} / \mathrm{z}$ calculated for $\mathrm{C}_{10} \mathrm{H}_{14} \mathrm{O}_{3} \mathrm{Na} 205.0841$, found $205.0830[\mathrm{M}+\mathrm{Na}]^{+}$. Data consistent with literature values. ${ }^{40}$

\section{The Hajos-Parrish-Eder-Sauer-Wiechert reaction.}

To a suspension of carbon nanostructures $(5 \mathrm{mg})$ in deuterated chloroform $(1 \mathrm{~mL})$ was added the organocatalyst $S$-(-)-proline (1.0 $\mathrm{mg}, 10 \mathrm{~mol} \%$ ), the combined suspension bath sonicated for $1 \mathrm{~min}$ at room temperature and then stirred for $1 \mathrm{hr}$ at room temperature. To this was added 2-methyl-2-(3oxobutyl)cyclopentane-1,3-dione $1(15.8 \mathrm{mg}, 87 \mu \mathrm{mol})$ and the mixture stirred for 7 days in the dark at room temperature. The solids were removed by filtration and the products of the reaction mixture characterised by ${ }^{1} \mathrm{H}$ NMR spectroscopy. Conversion of $\mathbf{1}$ and the selectivity of $\mathbf{2}$ to $\mathbf{3}$ was determined using the diagnostic methyl protons at $\delta_{\mathrm{H}}=1.10$ for $\mathbf{1}, 1.24$ for 2 and 1.32 ppm for 3. ${ }^{18}$ The pure products $\mathbf{2}$ and $\mathbf{3}$ were isolated by silica gel column chromatography (petroleum ether / ethyl acetate). $3 a$ - 
hydroxy-7a-methylhexahydro-1H-indene-1,5(6H)-dione $\quad 2: \quad \mathrm{R}_{\mathrm{f}}$ 0.22 (petroleum ether / ethyl acetate, $1 / 1) ;{ }^{1} \mathrm{H}$ NMR $\left(\mathrm{CDCl}_{3}\right)$ $\delta_{\mathrm{H}} / \mathrm{ppm} 3.23$ (br s, $\left.1 \mathrm{H}\right), 2.68-2.25(\mathrm{~m}, 6 \mathrm{H}), 2.09-1.92(\mathrm{~m}, 2 \mathrm{H})$, $1.83-1.63(\mathrm{~m}, 2 \mathrm{H}), 1.24(\mathrm{~s}, 3 \mathrm{H}) ;{ }^{13} \mathrm{C} \mathrm{NMR}\left(\mathrm{CDCl}_{3}\right) \delta_{\mathrm{C}} / \mathrm{ppm}$ 218.8, 208.8, 81.1, 52.5, 50.1, 36.4, 33.4, 32.5, 29.5, 13.9; HRMS $m / z$ calculated for $\mathrm{C}_{10} \mathrm{H}_{14} \mathrm{O}_{3} \mathrm{Na} 205.0841$, found $205.0841[\mathrm{M}+\mathrm{Na}]^{+} ;[\alpha]_{\mathrm{D}} /{ }^{\circ}\left(\mathrm{CHCl}_{3}, c\right.$ 1.0) +39.8. 7a-methyl2,3,7,7a-tetrahydro-1H-indene-1,5(6H)-dione $\quad 3: \quad \mathrm{R}_{\mathrm{f}} \quad 0.39$ (petroleum ether / ethyl acetate, $1 / 1) ;{ }^{1} \mathrm{H} \mathrm{NMR}\left(\mathrm{CDCl}_{3}\right) \delta_{\mathrm{H}} / \mathrm{ppm}$ 5.95 (s, 1H), 3.01-2.68 (m, 3H), 2.57-2.34 (m, 3H), 2.12-2.05 (m, $1 \mathrm{H}), 1.90-1.77(\mathrm{~m}, 1 \mathrm{H}), 1.32(\mathrm{~s}, 3 \mathrm{H}) ;{ }^{13} \mathrm{C} \mathrm{NMR}\left(\mathrm{CDCl}_{3}\right) 216.5$, 198.1, 169.7, 123.8, 48.6, 35.8, 32.8, 29.1, 26.7, 20.5; HRMS $m / z$ calculated for $\mathrm{C}_{10} \mathrm{H}_{12} \mathrm{O}_{2} \mathrm{Na}$ 187.0735, found $187.0725[\mathrm{M}+\mathrm{Na}]^{+}$; $[\alpha]_{\mathrm{D}} /{ }^{\mathrm{o}}\left(\mathrm{CHCl}_{3}, c\right.$ 1.0) +225.4 . Data consistent with literature values. ${ }^{41,42}$

\section{Conclusions}

We have shown for the first time the principle that non-covalent interactions between organocatalysts and carbon nanostructures can be used to control the yields and distribution of products in chemical transformations. We propose that the known transient interactions between the nitrogen of $S$-(-)-proline and the empty $\mathrm{C}=\mathrm{C} \pi^{*}$ orbital of carbon nanostructures (i) decrease the nucleophilicity of the nitrogen and therefore the catalytic activity towards ketone condensation and (ii) increase the acidity and thus activity for dehydration reactions in the Hajos-Parrish-EderSauer-Wiechert reaction. Although moderately small in magnitude, these effects are related to the external surfaces of carbon nanostructures, the extent of which can be readily modulated through variation of the diameter and thus pyramidalisation angle of the underlying carbon nanostructure. Whilst the addition of carbon nanostructures does not, under our experimental conditions, result in the selective formation of specific products of this classical organic transformation in high yields, our proof-of-principle study clearly shows that the pathways of chemical reactions can be controlled through noncovalent interactions with an auxiliary species, which is particularly attractive for organic synthesis as this approach is simple and does not involve the time and financially intensive functionalisation of catalyst molecules. Moreover, as the quality and availability of carbon nanotubes and related nanostructures continues to improve year-on-year, the ability to control the properties of the widest spectrum of preparative chemical transformations through interactions with nanocarbons is becoming increasingly viable. ${ }^{43-46}$ Of significance, our measurements have shown that carbon nanotubes are able to influence the strength of acidity of an amino acid. As controlling acidity is an important consideration for a broad variety of chemical transformations promoted by acids, further development of this concept may potentially offer a new synthetic tool to the field organic chemistry.

\section{Acknowledgements}

We would like to thank the European Research Council (ERC) and Engineering and Physical Science Research Council
(EPSRC) for funding, the Nottingham Nanotechnology and Nanoscience Centre (NNNC) for access to Raman spectroscopy facilities and Mr Scott Miners for assistance with manuscript preparation.

\section{Notes and references}

a School of Chemistry, University of Nottingham, University Park, Nottingham, NG7 2RD, U.K.

${ }^{b}$ Nottingham Nanotechnology \& Nanoscience Centre, University of Nottingham, University Park, Nottingham, NG7 2RD, U.K.

E-mail: Graham.Rance@nottingham.ac.uk, Fax:+44 (0)115 9513555.

$\dagger$ Electronic Supplementary Information (ESI) available: [control experiments in the absence of carbon nanostructures and additional spectroscopic measurements and titrations are described in the ESI]. See DOI: $10.1039 / \mathrm{b} 000000 \mathrm{x} /$

1 Catalysis: from principles to applications, ed. M. Beller, A. Renken and R. A. van Santen, Wiley-VCH, Weinheim, 2012.

2 Design and strategy in organic synthesis: from the Chiron approach to catalysis, ed. S. Giroux and B. L. Merner, Wiley-VCH, Weinheim, 2013.

3 Asymmetric organocatalysis: from biomimetic concepts to applications in asymmetric synthesis, ed. A. Berkessel and H. Groger, Wiley-VCH, Weinheim, 2005.

4 M. Movassaghi and N. Jacobsen, Science, 2002, 298, 1904.

5 B. List, Chem. Rev., 2007, 107, 5413.

6 W. Notz, F. Tanaka and C.F. Barbas III, Acc. Chem. Res., 2004, 37, 580.

7 B. List B, P. Pojarliev, W. T. Biller and H. J. Martin, J. Am. Chem. Soc., 2002, 124, 827.

8 B. List, J. Am. Chem. Soc., 2000, 122, 9336.

9 A. Alexaki and O. Andrey, Org. Lett., 2002, 4, 3611.

10 D. Enders and A. Seki, Synlett, 2002, 26.

11 B. List, P. Porjarliev and H. J. Martin, Org. Lett., 2001, 3, 2423.

12 N. Vignola and B. List, J. Am. Chem. Soc., 2004, 126, 450.

13 B. List, J. Am. Chem. Soc., 2002, 124, 5656.

14 J.-F. Briere, S. Oudeyer, V. Dalla and V. Levacher, Chem. Soc. Rev., 2012, 41, 1696.

15 Z. G. Hajos and D. R. Parrish, J. Org. Chem., 1974, 39, 1615.

16 U. Eder, G. Sauer and R. Wiechert, Angew. Chem. Int. Ed., 1971, 10, 496.

17 B. List, Tet., 2002, 58, 5573.

18 A. L. Fuentes de Arriba, L. Simon, C. Raposo, V. Alcazar and J. R. Moran, Tet., 2009, 65, 4841.

19 C. Allemann, R. Gordillo, F. R. Clemente, P. H. Y. Cheong and K. N. Houk, Acc. Chem. Res., 2004, 37, 558.

20 S. Niyogi, M. A. Hamon, H. Hu, B. Zhao, P. Bhowmik, R. Sen, M. E. Itkis and R. C. Haddon, Acc. Chem. Res., 2002, 35, 1105.

21 G. A. Rance, D. H. Marsh, R. J. Nicholas and A. N. Khlobystov, Chem. Phys. Lett., 2010, 493, 19.

22 Y. Maeda, M. Yamada, T. Hasegawa, T. Akasaka, J. Lu and S. Nagase, Nano, 2012, 7, 113001.

23 L. Piao, Q. Liu and Y. Li, J. Phys. Chem. C, 2012, 116, 1724.

24 A. Mavrandonakis, S. C. Farantos and G. E. Froudakis, J. Phys. Chem. $B, 2006,110,6048$.

25 T. Roman, W.A. Dino, H. Nakanishi and H. Kasai, Eur. Phys. D, 2006, 38, 117. 
26 C. Rajesh, C. Majumder, H. Mizuseki and Y. Kawazoe, J. Chem. Phys., 2009, 130, 124911.

27 D. Umadevi and G. N. Sastry, Chemphyschem, 2013, 14, 2570.

28 A. de Leon, A. F. Jalbout and V. A. Basiuk, Comp. Mater. Sci., 2008, 44, 310 .

29 A. de Leon, A. F. Jalbout and V. A. Basiuk, Chem. Phys. Lett., 2008, 457, 185.

30 A de Leon, A. F. Jalbout, V. A. Basiuk, Chem. Phys. Lett., 2008, 452, 306.

31 A de Leon, A. F. Jalbout, V. A. Basiuk, Int. J. Quantum Chem., 2010, 110, 953.

32 S.-Y. Ju, M. Utz and F. Papadimitrakopoulos, J. Am. Chem. Soc., 2009, 131, 6775.

33 Y. Wang and Y. Bu, J. Phys. Chem. B, 2007, 111, 6520.

34 O. V. Pupysheva, A. A. Farajian, H. Nejo, H. Mizuseki and Y. Kawazoe, Thin Solid Films, 2006, 499, 256.

35 D. J. Nelson and R. Kumar, J. Phys. Chem. C, 2013, 117, 3160.

36 G. Zheng, Z. Wang, S. Irle and K. Morokuma, J. Am. Chem. Soc., 2006, 128, 15117.

37 R. C. Haddon, Acc. Chem. Res., 1988, 21, 243.

38 Z. Chen, W. Thiel and A. Hirsch, Chemphyschem, 2003, 4, 93.

39 X.-S. Xue, C. Yang, X. Li and J.-P. Cheng, J. Org. Chem., 2014, 79, 1166.

40 M. Limbach, Tet. Lett., 2006, 47, 3843.

41 S. Rohrig, L. Hennig, M. Findisen, P. Welzel and D. Muller, Tet., 1998, 54, 3439.

42 S. G. Davies, A. J. Russell, R. L. Sheppard, A. D. Smith and J. E. Thomson, Org. Bio. Chem., 2007, 5, 3190.

43 B. Li and Z. Xu, J. Am. Chem. Soc., 2009, 131, 16380.

44 G. A. Rance, S. A. Miners, T. W. Chamberlain and A. N. Khlobystov, Chem. Phys. Lett., 2013, 557, 10.

45 B. Frank, R. Blume, A. Rinaldi, A. Trunschke and R. Schlogl, Angew. Chem. Int. Ed., 2011, 50, 10226.

46 D. R. Dreyer, H.P. Jia and C. W. Bielawski, Angew. Chem. Int. Ed., 2010, 49, 6813. 